$\left[\begin{array}{lll}\text { 衛 } & \text { EISEI } & \text { KAGAKU } \\ 33(2) & \text { 华 } & \text { 学 } \\ 33-97 & (1987)\end{array}\right]$

高速液体クロマトグラフィーによるポリ塩化ビニル製品中の無水フタル酸の定量

五十嵐良明，小殦茂雄，鹿庭正昭，中村晃忠

国立衛生試験所

\title{
Determination of Phthalic Anhydride in Poly (vinyl chloride) Products by High Performance Liquid Chromatography
}

\author{
Yoshiaki Ikarashi, Shigeo Kojima, Masa-AKi Kaniwa \\ and Akitada Nakamura \\ National Institute of Hygienic Sciences, 1-18-1, Kamiyoga, \\ Setagaya-ku, Tokyo 158, Japan
}

(Received August 7, 1986)

\begin{abstract}
A method for the determination of phthalic anhydride (PA) in poly (vinyl chloride) (PVC) products by reversed-phase high performance liquid chromatography (HPLC) is described. By the reaction of PA with ethanol, PA is converted to monoethyl phthalate (MoEP), which is further methylated to methyl ethyl phthalate (MEP) with diazomethane. PA could be successfully determined by quantitating MEP.

The method is as follows : one gram of chopped PVC sample and $10 \mathrm{mg}$ of $\mathrm{Ca}, \mathrm{Zn}$ stearate are dissolved in $10 \mathrm{ml}$ of dehydrated tetrahydrofuran. Ten milliliter of ethanol is added to the solution, and the solution is refluxed for $20 \mathrm{~min}(\mathrm{PA} \rightarrow \mathrm{MoEP})$. PVC polymer is precipitated by the addition of methanol, and removed by filtration. After shaking the filtrate with cation-exchange resin, MoEP is methylated with diazomethane ( $\mathrm{MoEP} \rightarrow \mathrm{MEP}$ ). The reaction mixture is loaded on a silica gel column, and washed with $50 \mathrm{ml}$ of diethyl ether-hexane (5:95) mixture, and eluted with $50 \mathrm{ml}$ of diethyl ether-hexane $(10: 90)$ mixture. The eluate is evaporated to dryness, and the residue is redissolved in $1 \mathrm{ml}$ of methanol. Five microliter of this solution is injected to HPLC apparatus. HPLC conditions : column, Nucleosil $5 \mathrm{C}_{8}(250 \mathrm{~mm} \times 4.6 \mathrm{~mm}$ i.d.); mobile phase, acetonitrile-water (60:40); flow rate, $1.0 \mathrm{ml} / \mathrm{min}$; detector, ultraviolet detector; detection wavelength, $254 \mathrm{~nm}$.

Calibration curve based on the peak height of MEP was found to be linear in a wide range of 2-1000 $\mu \mathrm{g}$ of PA. However, the amounts of PA found in PVC products were only less than 2.6 $\mu \mathrm{g} / \mathrm{g}$.
\end{abstract}

Keywords-determination; phthalic anhydride; poly(vinyl chloride) product; derivatization; methyl ethyl phthalate; HPLC

\section{緒 言}

無水フタル酸 $(\mathrm{PA})$ は反応性が高く, 皮膚や上気道を 刺激するため，PAを取り报う職場において PA による 皮膚炎1) や気管支喘息 ${ }^{2,3)}$ の発生が報告されている。最 近, 道祖土ら ${ }^{4)}$ は軟質ポリ塩化ビニル (PVC) 製品中か ら0.7\%の PA を検出したと報告している。著者らはこ の報告に注目し，このように多量の PA が PVC 製品中 に含まれているとすれば，家庭用手袋によるかぶれらな ぞ PVC 製品による事故が PA によって起こっている
可能性があり，市販の PVC 製品中のPA の含有量を 把握する必要があると考完た。

PA は反応性の高い不安定な化合物であり，その正確 な定量は難しい，道祖士ら な誘導体に変換することなくそのままガスクロマトグラ フィー（GC）により定量する方法をとっているが，著者 らが追試したところでは，前処理の段階でPA がメタノ 一ルと反応してロスするため，低い回収率しか得ること ができなかった。 
一方，PA を安定な誘導体に変換して定量する方法と しては,アルキド樹脂中の PA をつタル酸に変換後, 水 酸化カリウムにより滴定する方法 ${ }^{6}$ や PA を硫酸酸性 のェタノールでフタル酸ジェチル (DEP) に変換後, GC で分析する方法》がある。しかしながら，PVC 製品中 には DEP やフタル酸が可塑剤（あるいは他の可塑剈中 の不純物）やその分解生成物として含まれている可能性 があるので，PAをこれらの化合物に変換して分析する のは適切な方法とはいえない。

そこで著者らは，PAをェタノールと反応させてフタ ル酸モノエチル (MoEP) とし，更にこれをジアゾメタ ンによりメチル化して通常は PVC 製品中に含まれるこ とのないフタル酸メチルエチル (MEP) に変換して, 高 速液体クロマトグラフィー（HPLC）により定量する方 法を確立し，市肘の PVC 製品の分析にも応用した。

\section{実 験 方 法}

1. 試料 市眅軟質 PVC 製品 9 種 (Table II).

2. 試薬無水フタル酸 (PA) 襟集液——和光純 薬工業㹈の特級品をつセトンに溶かし, 必要な濃度の溶 液を調製して用いた。

フタル酸メチルェテル (MEP) 標準液——タル酸モ ノェチル (MoEP; 和光純薬工業製の特級品)をジアゾ メタンでメチル化したものをメタノールに溶かし，1 $\mathrm{mg} / \mathrm{ml}$ の濃度の溶液を調製し，適宜希釈して用いた。

フタル酸エステル類——タル酸ジチル (DMP), $\mathrm{DEP}$ 、フタル酸ジーnーブチル (DBP) 並びにフタル酸ジ (2-エチルヘキシル) (DEHP) はいずれる東京化成製の 特級品を用いた。

ステアリン酸カルシウム・巠鉛（ステアリン酸 $\mathrm{Ca}$, $\mathrm{Zn}$ )——テルモ社製のPVCフィルム用安定剤; ェポキ シ化大豆油中にステアリン酸亜鉛を $10.16 \%$ ，ステアリ ン酸カルシウムを $7.58 \%$ 含む.

テトラヒドロフラン (THF) 一一和光純薬工業製の特 級品に水素化カルシウムを加光，24時間放置して脱水し た後, 蒸留して $66^{\circ} \mathrm{C}$ て留出する留分をとり，無水硫酸ナ トリウムを加克て密栓して保存したもの.

アセトニトリル—和光純薬工業製の高速液体クロマ トグラフィー用.

陽イオン交換樹脂—ロームフンドハース社製 Amberlyst (非水系用).

シリカゲルー-Merck 社製 Kieselgel 60 (70-230 mesh).

他の試薬はいずれも市眅の特級品を用いた。

3. 装置及び器具高速液体クロマトグラフ—島 津 LC-3 A 型汇島津 SPD-2 A 型紫外部検出器を接続し
て用いた。

クロマト管一内径 $10 \mathrm{~mm}$, 長さ $30 \mathrm{~cm}$ の活栓付き ガラス製クロマト管.

マイクロシリンジ—-Hamilton 社製， $25 \mu 1$ 用.

4. HPLC 条件 カラム: Nucleosil $5 \mathrm{C}_{8}$ カラム (Nagel 社製, 盖径 $5 \mu \mathrm{m}, 250 \mathrm{~mm} \times 4.6 \mathrm{~mm}$ i.d.)； 移動相：アセトニトリルー水 $(60: 40)$; 流速 : $1.0 \mathrm{ml}$ / $\min$; 測定波長 : $254 \mathrm{~nm}$.

5. 定量法 標準添加法による操作について記す。

5-1 試験溶液の調製—PVC 製品を細切し， 5 個の $50 \mathrm{ml}$ のナス型フラスコに $1.00 \mathrm{~g}$ ずつ精种して入れる. これらのナス型フラスコにそれぞれ０（然添加），2，5， 8 及び $12 \mu \mathrm{g}$ の PA を加え, 更にステアリン酸 $\mathrm{Ca}, \mathrm{Zn}$ 各 $10 \mathrm{mg}$ 及び $\mathrm{THF}$ 各 $10 \mathrm{ml}$ を加えて, マグネチック スターラーで 1 時間かき混ぜて PVCを溶かす。得られ た溶液にェターール $10 \mathrm{ml}$ を加光，20分間加熱・還流寸 る $(\mathrm{PA} \rightarrow \mathrm{MoEP})$. 反応液叱メターール $10 \mathrm{ml}$ を加えて PVC を析出させ，万過して除く。万液に Amberlyst 3 $\mathrm{g}$ を加えて30分間振り混ぜた後, 万過して溶媒を留去す る.残留物を酢酸エチル $1 \mathrm{ml}$ 飞溶かし, 常法に上り調 製したジアジメタン・ジェチルェーテル溶液 $1 \mathrm{ml}$ を加 えて30分間放置する (MoEP $\rightarrow \mathrm{MEP})$. 溶媒を留去し, 残留物をジェチルエーテルーへキサン $(5: 95)$ 混液 2

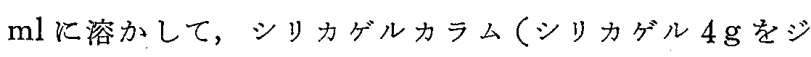
エチルエーテルーヘキサン（5：95）混液を用いて湿式法 によりクロマト管に充填したもの）飞負荷する。まずジ エチルェーテルーーキサン（5：95）混液 $50 \mathrm{ml}$ で洗浄 し，次にジェチルェーテルーヘキサン $(10: 90)$ 混液 50 $\mathrm{ml}$ を通して，溶離液を分取する，溶離液から溶媒を留 去し，残留物をメタノール $1 \mathrm{ml}$ 儿溶かして試験溶液と する．操作法をChart 1 火示した。

5-2 定量操作一一得られた 5 種の試験溶液からマイ クロシリンジにより各 $5 \mu \mathrm{l}$ を採り, HPLC 装置に注入 する。得られたクロマトグラム上の MEPのピーク高さ を縦軸に，PA 添加量を横軸にとってグラフ上にプロッ トし，最小二乗法に上り得られた回帰直線之横軸の交点 から試料中の $\mathrm{PA}$ 量を求める.

\section{結果及び考察}

\section{MEP と他のフタル酸エステル類との分離}

通常 MEP は PVC 製品中に含まれて和らず，PVC 製品中のPA を定量するのに適した誘導体と考兄られ る.

そこで, MEP, DMP, DEP, DBP, 及び DEHP の 5 種のフタル酸エステルを用いて分離条件を検討した．そ の結果, 本法の HPLC 条件で MEP が DMP や DEP 


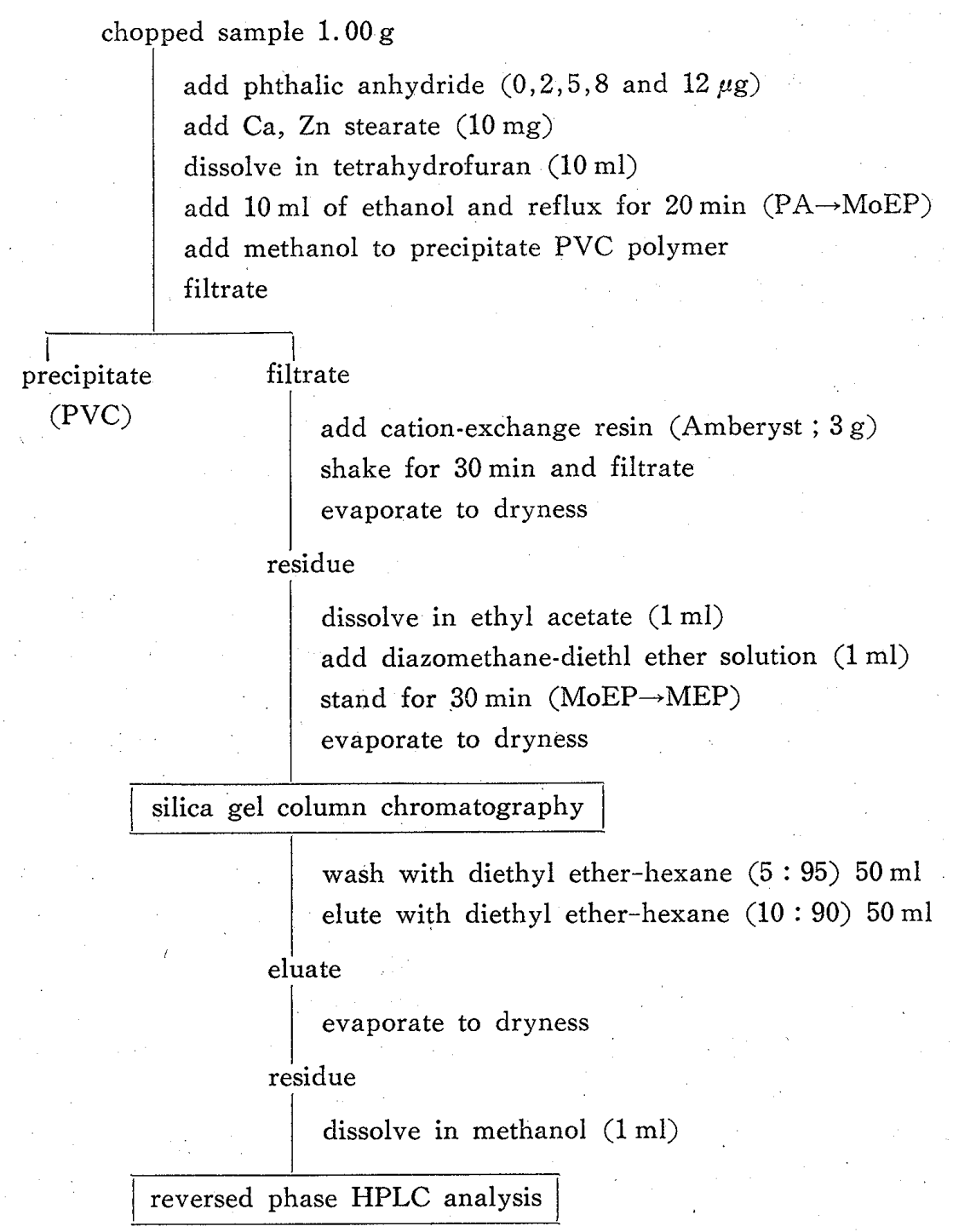

Chart 1. Analytical Procedure for Phthalic Anhydride in Poly (vinyl chloride) Products by Standard Additition Method

と良好に分離されることが分かった（Fig，1).

したがって，PA $\rightarrow \mathrm{MoEP} \rightarrow \mathrm{MEP}$ の変換（Fig. 2 a) が定量的であれば，生成した MEPを HPLCで分析す ることにより，PVC 製品中のPA を正確に定量できる ものと考克られる。

\section{2. $\mathrm{PA} \rightarrow \mathrm{MoEP}$ の変換}

本法では PVC 製品から PA を抽出するのに試料を 一度 THF に溶かした後，メタノールを加えて PVCを 析出させ，ろ過して除く方法を採用した。そこで，THF の存在下に括いて PA $\rightarrow \mathrm{MoEP}$ の変換が定量的に進むよ らな反応条件を検索した，PA $\rightarrow \mathrm{MoEP}$ の変換率は，生 成した MoEP をメチル化して MEP とした後 HPLC で定量して求めた。

2-1 ステアリン酸 $\mathrm{Ca}, \mathrm{Zn}$ 添加の効界 まず, PA $1000 \mu \mathrm{g}$ をェタノール $10 \mathrm{ml}$ に溶かて, THF を加えず
に20分間加熱 ・還流した場合には $\mathrm{PA} \rightarrow \mathrm{MoEP}$ の変換率 は $96 \%$ と定量的であった：これに対して，THF $10 \mathrm{ml}$ 共存させて同様の操作を行った場合の变換率は $14 \%$ に過 ぎず，THF の存在はPA とエタノールの反応を抑制す ることが分かった。

こらしたことから，THF の存在下において $\mathrm{PA \rightarrow}$ $\mathrm{MoEP}$ の変換を促進する効果をもつものがないか種从 の化合物を加壳て検討したところ，PVC の安定剂の 1 つであるステアリン酸 $\mathrm{Ca}, \mathrm{Zn}$ が促進効果を示した.

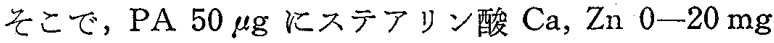
を加えて THF $10 \mathrm{ml}$ に溶かし, 更にェタノール $10 \mathrm{ml}$ を加党て20分間加熱・還流した後, Amberlyst $3 \mathrm{~g}$ と振 り混ぜた場合の $\mathrm{PA} \rightarrow \mathrm{MoEP}$ の変換率を検討した. その 結果, MoEP への变換率はステアリン酸 $\mathrm{Ca}, \mathrm{Zn}$ の添加 量が增すとともに高くなるが，10 mg 以上ではほぼ一定 


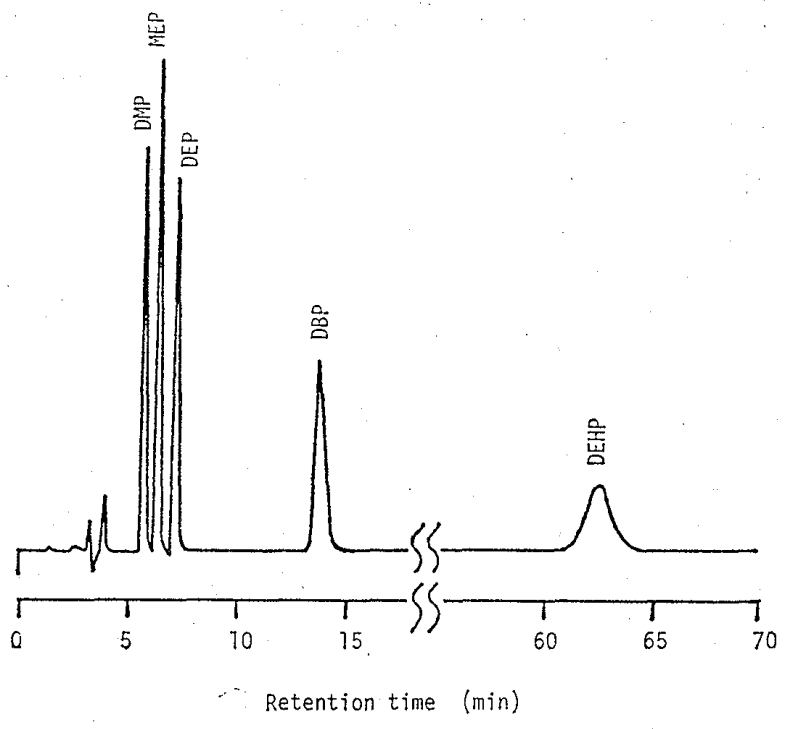

Fig. 1. Chromatogram of a Mixture of Phthalate Standards

Peaks : DMP; dimethyl phthalate, MEP; methyl ethyl phthalate, DEP ; diethyl phthalate, DBP ; dibutyl phthalate, DEHP ; di(2-ethylhexyl) phthalate.

HPLC conditions : column; Nucleosil $5 \mathrm{C}_{8}$ (Nagel, Particle size $5 \mu, 250 \mathrm{~mm} \times 4.6 \mathrm{~mm}$ i.d.), mobile phase ; acetonitrilewater $(60: 40)$, flow rate $; 1.0 \mathrm{ml} / \mathrm{min}$, detector; ultraviolet detector, detection wavelength ; $254 \mathrm{~nm}$.

となることが分かった（Fig. 3).

以上の結果から，本法に抹いては PVC 製品 $1 \mathrm{~g}$ に対 してステアリン酸 $\mathrm{Ca}, \mathrm{Zn} 10 \mathrm{mg}$ を加えて操作すること とした.

なお，ステアリン酸 $\mathrm{Ca}, \mathrm{Zn}$ が $\mathrm{PA} \rightarrow \mathrm{MoEP}$ の変換を 促進するメカニズムについては不明であり，更に検討が 必要である。

2-2 THF 中の水の影響 市眨の THF 中には水 がかなり含まれており，試料を溶かす操作の間にPAの
一部が加水分解を起こしてフタル酸に変化する可能性が める(Fig. 2 b).

そこで，市販の THF をそのまを用いた場合とこれを 水素化カルシウムで脱水後蒸留したTHFを用いた場合 とを比較した。すなわち，PA $1000 \mu \mathrm{g}$ 及びスデアリン 酸 $\mathrm{Ca}, \mathrm{Zn} 10 \mathrm{mg}$ を市販の THF あるいは蒸留した THF $10 \mathrm{ml}$ に溶かし，マグネチックスターラーで 1 時 間かき混ぜた後，エタノール10 ml を加えて20分間加熱 ・還流した。以下定量法に準じて操作し，得られたクロ マトグラムを比較した。

Fig. 4 に示したよらに，市販の THF をとのまま用 いた場合には、フタル酸由来の DMP の大きなピークが 諗められ，添加したPA がかなり加水分解を起こしてい るこ之が分かったＰA の MEP としての回収率も59\% に過ざなかった。

これに対して，脱水後蒸留したTHFを用いた場合に は，DMP のピークはかなり小さくなり，PA の回収率 も90\%まで上昇した。蒸留した THF を用いても DMP のピークが完全には消失しなかったのは, 蒸留した THF の保存中や PVC の溶解操作中に THF が吸湿す るためと考光られる。

\section{MoEP $\rightarrow$ MEP の変換}

遊離の MoEP は, 眽酸エチル $1 \mathrm{ml}$ に溶かし, 氷冷 下でジアゾメタン・ジェチルエーテル溶液 $1 \mathrm{ml}$ を加え て30分間放置することによって, 定量的に MEP に変掺 される。

3-1 陽イオン交換樹脂による処理 ステアリン酸 $\mathrm{Ca}, \mathrm{Zn}$ の添加により $\mathrm{PA} \rightarrow \mathrm{MoEP}$ の変換は促進される が，生成した MoEP の一部がカルシウムや亜鉛の塩と なってジアゾメタンではメチル化されなくなる。このた め，ステアリン酸 $\mathrm{Ca}, \mathrm{Zn}$ を加えて操作した後, 陽イオ<smiles>O=C1OC(=O)c2ccccc21</smiles>

phthalic anhydride (PA)

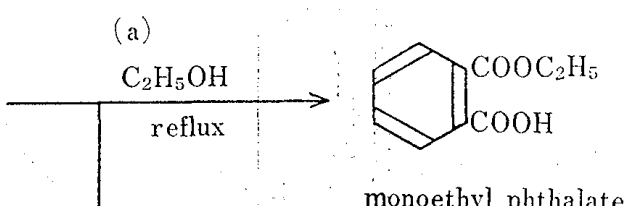

(MoEP)

(b)<smiles>O=C(O)c1ccccc1C(=O)O</smiles>

phthalic acid

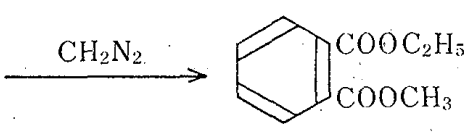

methyl ethyl phthalate (MEP)

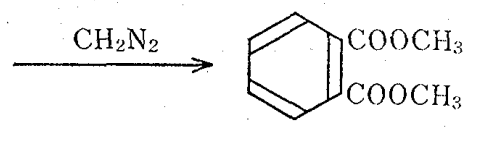

dimethyl phthalate (DMP)

Fig. 2. Conversion of Phthalic Anhydride to Methyl Ethyl Phthalate (a) and Dimethyl Phthalate (b) 


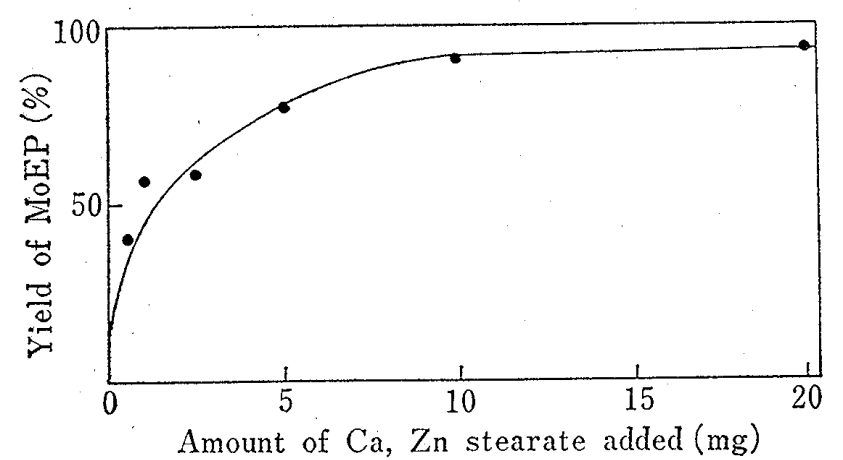

Fig. 3. Effect of Addition of $\mathrm{Ca}, \mathrm{Zn}$ Stearate on the Yield of Monoethyl Phthalate in the Presence of Tetrahydrofuran (THF)

Fifty microgram of $\mathrm{PA}$ and $0-20 \mathrm{mg}$ of $\mathrm{Ca}, \mathrm{Zn}$ stearate were dissolved in a mixture of $10 \mathrm{ml}$ of THF and $10 \mathrm{ml}$ of ethanol, and the solution was refluxed for $20 \mathrm{~min}$. After shaking the reaction mixture with cation-exchange resin (Amberlyst), MoEP was methylated to MEP with diazomethane and determined by HPLC method. HPLC conditions used were the same as those in Fig. 1. (a)

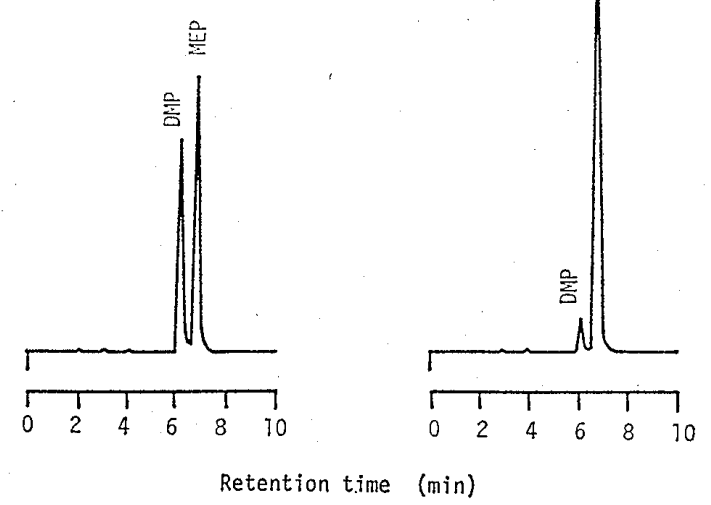

Fig. 4. Effect of Dehydration of Tetrahydrofuran on the Conversion of Phthalic Anhydride to Methyl Ethyl Phthalate

(a) commercial THF, (b) dehydrated THF.

Peaks : DMP; dimethyl phthalate, MEP; methyl ethyl phthalate.

One thousand microgram of $\mathrm{PA}$ and $10 \mathrm{mg}$ of $\mathrm{Ca}, \mathrm{Zn}$ stearate was used for the experiment. Other procedures were the same as those described in Fig. 3.

ン交換樹脂による処理を行わなかった場合には，PA 添

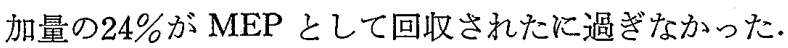

そこで，反応液に非水系用の陽イオン交換樹脂である Amberlyst を加光て振り混ぜ, MoEP のカルシウムや 覀鉛の塩を遊離の MoEP とした後,メチル化する方法 について検討した。すなわち，MoEP のカルシウム塩 $1000 \mu \mathrm{g}$ を THF-エタノールーメタノール (5:10:5) 混液 $20 \mathrm{ml}$ に溶かし, Amberlyst $3 \mathrm{~g}$ を加えて30分間振
り混ぜた後にメチル化して分析したところ，添加した MoEP のカルシウム塩の $96 \%$ が MEP となって検出さ れた。

\section{4. シリカゲルカラムクロマトグラフィーによるクリ ーンアップ}

軟質 PVC 製品からは多量の DEHP が抽出されてく るため，抽出液を气のまま HPLC 分析するのは分析に 長時間を要するだけでなく，分離カラムを污す原因にも なる、そこでシリカゲルカラムによる DEHP の除去を 試みた。

DMP, MEP, DEP, DBP 及び DEHP (各 $1000 \mu \mathrm{g}$ ) をジェチルェーテルーヘキサン（5:95）混液 $2 \mathrm{ml}$ に溶 かしてシリカゲルカラム（シリカゲル $4 \mathrm{~g}$ をジェルエ ーテルーヘキサン（5：95）混液を用いて湿式法によりク ロマト管に充填したもの）に負荷した後，ジェチルェー テルーヘキサン $(5: 95)$ 混液 $50 \mathrm{ml}$ 及び $(10: 90)$ 混液 $50 \mathrm{ml}$ で溶離し（それぞれ第 1 画分及び第 2 画分とす る)，これらのフタル酸エステル類の溶出パターンを検 討した。その結果，まず第 1 画分飞 DBP 及び DEHP が溶出し，次いで第 2 画分に DMP，MEP 及び DEP が溶出することが分かった。

次に，軟質 PVC 製品のように DEHP 量が PA 量 に比べて圧倒的に多い場合を想定して，DEHP $200 \mathrm{mg}$ と MEP $50 \mu \mathrm{g}$ の混合物を用いて同様の検討を行った. この場合には，DEHP のほとんぞは第 1 画分に溶出し たが，第 2 画分にも一部検出された。一方，MEP はこ

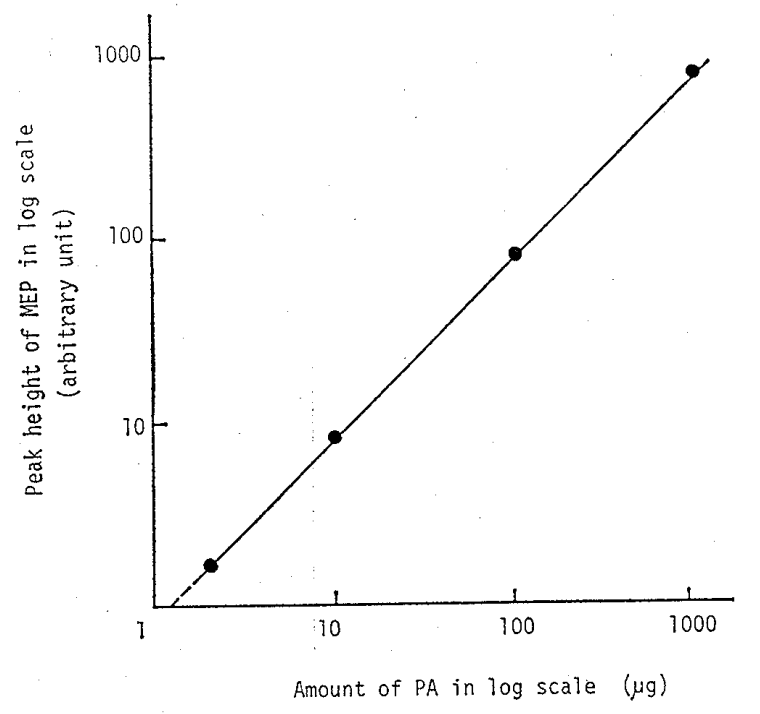

Fig. 5. Calibration Curve for Phthalic Anhydride

PA $(2-1000 \mu \mathrm{g})$ was added to $1.00 \mathrm{~g}$ of chopped sample (No. 2 in Table II), and determined by the proposed method. 
TABLE I. Reproducibility of Peak Height Value as a Function of Amount of PA added

\begin{tabular}{|c|c|c|c|c|c|c|c|}
\hline \multirow{2}{*}{$\begin{array}{l}\text { PA added } \\
(\mu \mathrm{g})\end{array}$} & \multicolumn{7}{|c|}{ Peak height (arbitrary unit) } \\
\hline & No 1 & 2 & 3 & 4 & 5 & $\operatorname{mean}( \pm \text { S.D. })^{a)}$ & R.S.D. ${ }^{b)}(\%)$ \\
\hline 2 & 1.15 & 1.40 & 1.30 & $\left(2.40^{c}\right)$ & 1.25 & $1.28 \pm 0.10$ & 8.16 \\
\hline 10 & 9.30 & 8.00 & 8.20 & 8.55 & 8.00 & $8.41 \pm 0.55$ & 6.49 \\
\hline 100 & 74.4 & 79.2 & 72.0 & 75.2 & 74.8 & $75.1 \pm 2.60$ & 6.75 \\
\hline 1000 & 824 & 830 & 824 & 808 & 824 & $822 \pm 8.25$ & 1.00 \\
\hline
\end{tabular}

a) S.D. : standard deviation.

b) R.S.D. : relative standard deviation.

c) This value was abandoned as an unusual value based on the result of Smirnoff's gap test at $p<0.01$ (Ref. 8).

の場合にも第 2 画分に定量的に溶出することが分かっ た.そこで，ジェチルエーテルーヘキサン (5:95) 混液の 量を增して, DEHP が溶出しきってから (10:90) 混液 を流して，MEP を溶出しよらと試みたが，100 $\mathrm{ml}$ まで 増すと DEHP がまだ溶出しきらないにもかかわらず MEP の一部が第 1 画分に溶出するようになり良好な結 果が得られなかった。

このように，本法を実際の PVC 製品の分析に適用す る場合，試験溶液から DEHP を完全には除去できてい ないため，分析に長時間かかるという問題点が残されて 和り，この点については今後更に検討が必要である。

\section{5. 本法の適用範囲}

Table II, No. 1 の試料 $1.00 \mathrm{~g}$ にPA を 2,10 , 100 あるい性 $1000 \mu \mathrm{g}$ 加光, 定量法に準じて操作し, 得 られたクロマトグラム上の MEP のピーク高さを PA の添加量に対して両対数グラフ上にプロットしたとこ ろ，Fig. 5 のように良好な直線性を示し，本法により PVC 製品中のPA を広い濃度崭囲にわたって定量でき ることが分かった。

Table I Kは，各添加量において5 回繰り返し実験し た場合の MEP のピーク高さの測定值と相対標準偏差を 示した。相対標準偏差はいずれも $8 \%$ 以下であった.

\section{6. 市販試料の分析}

あらかじめ試験的にいくつかの PVC 製品について分 析したところ，PA はごく少量しか含まれていないこと が分かったので，標準添加法による定量を試みた。

Table II の 9 種の試料を本法 (標準添加法)により分 析し, 得られたクロマトグラム上の MEP のピーク高さ をPA の添加量に対してプロットしたところ，いずれの 試料においても相関係数 0.98 以上の良好な直線性を示 し，その横軸切片から試料中のPA 量を求めることがで きた。

クロマトグラムの1例を Fig. 6 に，また分析結果を Table II に示した。著者らが検討した範囲では，PVC 製品中の PA 含有量の最大值は $2.6 \mu \mathrm{g} / \mathrm{g}$ で, 道祖土ら
の報告4) にある $0.7 \%(7000 \mu \mathrm{g} / \mathrm{g})$ というレベルより もはるかに少なかった。

PVC 製家庭用手袋化よる接触皮算炎患者 3 名がいず れも $1 \% \mathrm{PA}$ のパッチテストに対して陰性の反応を示し たといら関東らの知見 ${ }^{92}$ から考えると，今回検出された レベルのPA では事故の原因となっている可能性は少な いと思われる。

\section{7. 道祖土らの方法 ${ }^{4}$. について}

(1) PA $5 \mathrm{mg}$, (2) Table II, No. $21.00 \mathrm{~g}$ に PA $5 \mathrm{mg}$ を添加したもの, (3) Table II, No.2 $1.00 \mathrm{~g}$ の 3 種を 試料に用いて道祖土らの方法 ${ }^{4)}$ の追試を行ったところ，

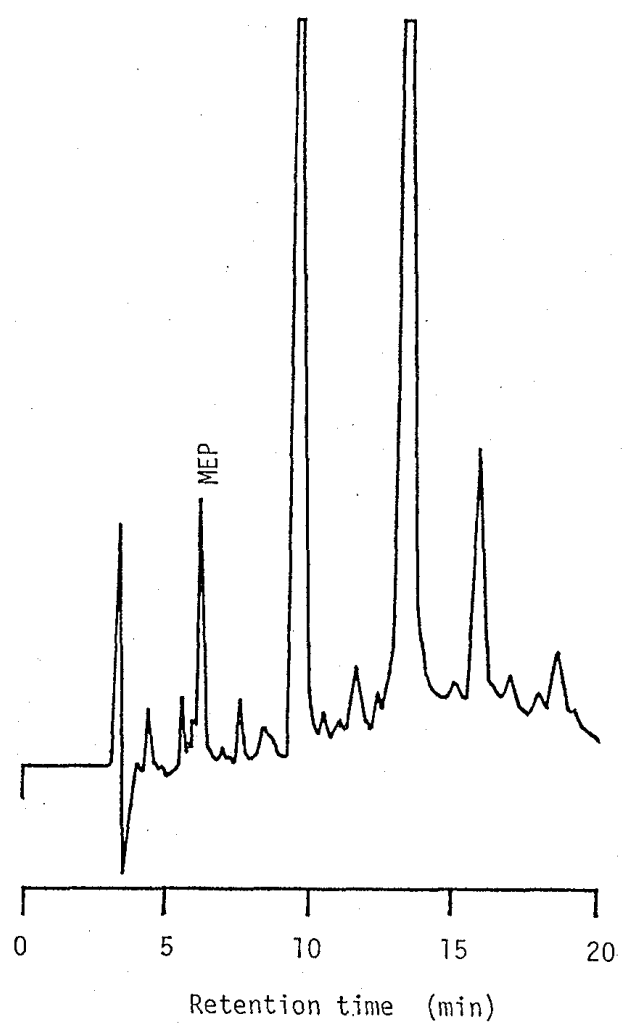

Fig. 6. Chromatogram for Sample No. 1 in Table II Spiked with $5 \mu \mathrm{g}$ of Phthalic Anhydride

HPLC conditions were the same as those in Fig. 1. 
TABLE II. Analytical Results of Phthalic Anhydride in Poly (vinyl chloride) Products

\begin{tabular}{|c|c|c|c|}
\hline No. & Sample & Source & $\begin{array}{l}\text { Phthalic anhydride } \\
\text { found }(\mu \mathrm{g} / \mathrm{g})^{a}\end{array}$ \\
\hline 1 & Chamber ${ }^{b)}$ (hard type) & Eiken Kizai Co., Ltd. & $\mathrm{ND}^{e)}$ \\
\hline 2 & Chamber (medium type) & & 2.49 \\
\hline 3 & Chamber (soft type) & & 2.55 \\
\hline 4 & Tube $^{b)}$ & & 0.45 \\
\hline 5 & Tube & & $1: 80$ \\
\hline 6 & Pelet $^{()}$ & & 0.12 \\
\hline 7 & Pelet & & 1.33 \\
\hline 8 & Domestic gloves $^{(\overrightarrow{)})}$ & Toho University & ND \\
\hline 9 & Domestic gloves & & 0.36 \\
\hline
\end{tabular}

a) Average value $(n=3)$.

b) Used for medical devices.

c) Source material of PVC products.

d) Suspected to be the causative product of contact dermatitis.

e) Not detected.
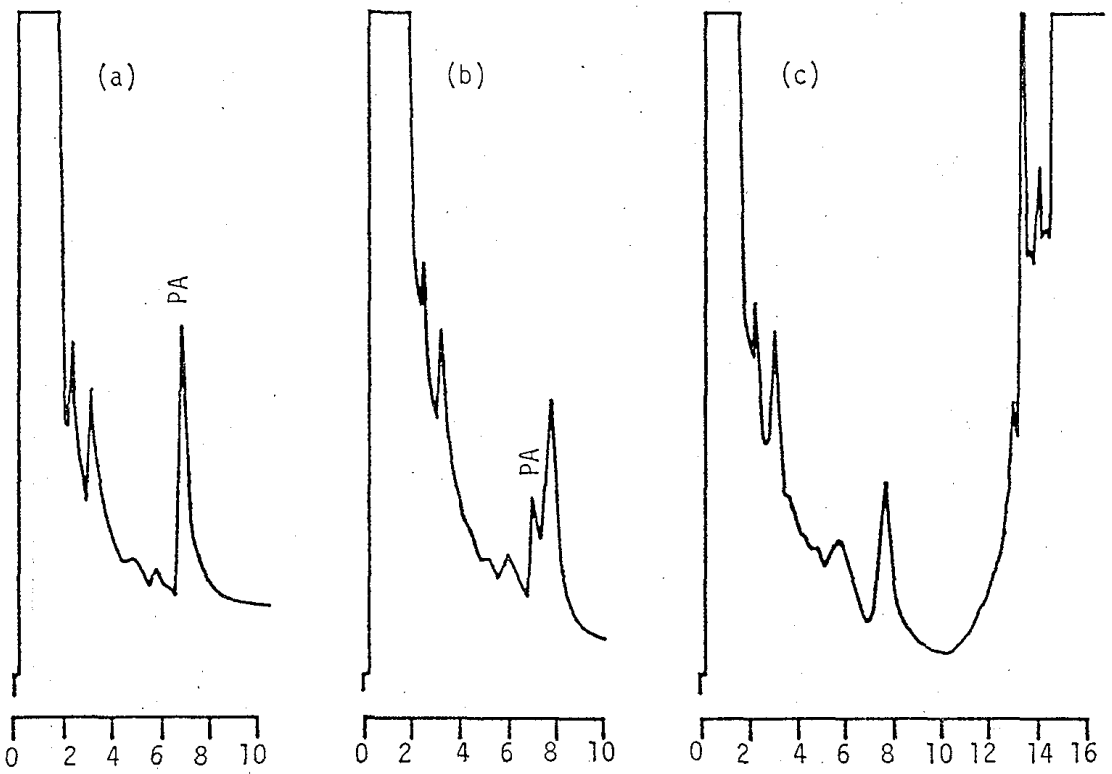

Retention time (min)

Fig. 7. Gas Chromatograms by Modified Saido's Method ${ }^{a}$
(a) PA $5 \mathrm{mg}$
(b) Sample No. 1 in Table II $1.00 \mathrm{~g}+$ PA $5 \mathrm{mg}$.
(c) Sample No. 1 in Table II $1.00 \mathrm{~g}$
a) Temperature-gradient condition was different from original method (Ref. 4).
GC conditions : column; $5 \%$ OV-17 on Shimalite W (80-100 mesh), $1 \mathrm{~m} \times 3 \mathrm{~mm}$ i.d., column temperature; hold at $135^{\circ} \mathrm{C}$ for $10 \mathrm{~min}$, then raised to $295^{\circ} \mathrm{C}$ at the rate of $20^{\circ} \mathrm{C} /$ $\mathrm{min}$, injection port and detector temperature; $300^{\circ} \mathrm{C}$, carrier gas; $\mathrm{N}_{2}$, flow rate $; 30 \mathrm{ml} / \mathrm{min}$.

PA だけの場合 (1)）の回収率は $31 \%$ であり，をた PVC 製品に PA を添加した場合. (2)）にはわずか $8 \%$ であっ た (Fig. 7).このように回収率が惎かったのは, 前処理 の段階で PA が THF の水や添加したメタノールと反 応してロスしてしまったためと考えられる。

こうしたことから，道祖土らの方法4)は PVC 製品中
のPA の定量分析に用いるには適当でないと考兄られ る.

また，本法による定量值 $(2.6 \mu \mathrm{g} / \mathrm{g}$ 以下) と道祖土ら の報告4) に专る値 $(7000 \mu \mathrm{g} / \mathrm{g})$ との間の大きな食い違い の原因については，道祖土らの試料を分析していないの ではっきりとは分からない。しかしながら，Table II の 
試料を道祖土らの方法4)によって分析したところ, Fig. $7 \mathrm{c}$ に 1 例を示したように，いずれの陚料からも PAを 検出でさなかったことは，PVC 製品中のPA の含有量 はごく少ないという本法の分析結果を裏付けるものと考 えられる。

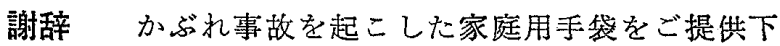
さいました東邦大学・(故) 石原教授, 並びに種々の PVC 製品をご提供下さい亡した栄研器材秼に深謝致し ます。

\section{引用 文 献}

1）木藤寿正, 鳥栖研一, 労働科学, 29, 625 (1953).

2) 太田武夫, 原 一郎, 宮城信雄, 産業医学, 20, 228 (1978).

3) M.J. Ward, D. Davies, Clin. Allergy, 12, 165 (1982).

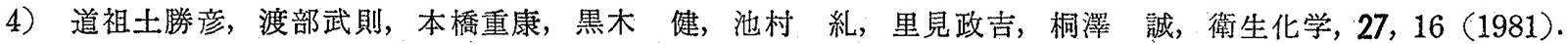

5) 厚生省生活衛生局家庭用品安全対策室, “家庭用品に係る健康被害病院モニター報告（5年間のまとめ）， 1984.

6) R. Prakash, Paintindia, 33, 8 (1983).

7) E.A. Kruglov, L.G. Tsypysheva, G.D. Kharlampovich, T.V. Portnova, Zh. Anal. Khim., 35, 122 (1980).

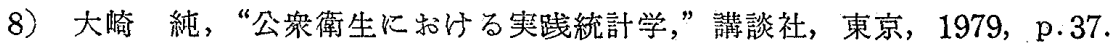

9）石原 勝，関東裕美，末発表データ. 